\title{
Reversals in initially denied Department of Veterans Affairs' PTSD disability claims after 17 years: a cohort study of gender differences
}

Maureen Murdoch ${ }^{1,2,3^{*}}$, Michele Roxanne Spoont ${ }^{2,3,4,5}$, Nina Aileen Sayer ${ }^{2,3,5}$, Shannon Marie Kehle-Forbes $2,3,6$ and Siamak Noorbaloochi ${ }^{2,3}$

\begin{abstract}
Background: In 2011, the Department of Veterans Affairs (VA) strengthened its disability claims processes for military sexual trauma, hoping to reduce gender differences in initial posttraumatic stress disorder (PTSD) disability awards. These process improvements should also have helped women reverse previously denied claims and, potentially, diminished gender discrepancies in appealed claims' outcomes. Our objectives were to examine gender differences in reversals of denied PTSD claims' outcomes after 2011, determine whether disability awards (also known as "service connection") for other disorders offset any PTSD gender discrepancy, and identify mediating confounders that could explain any persisting discrepancy.
\end{abstract}

Methods: From a nationally representative cohort created in 1998, we examined service connection outcomes in 253 men and 663 women whose initial PTSD claims were denied. The primary outcome was PTSD service connection as of August 24, 2016. Secondary outcomes were service connection for any disorder and total disability rating. The total disability rating determines the generosity of Veterans' benefits.

Results: $51.4 \%$ of men and $31.3 \%$ of women were service connected for PTSD by study's end ( $p<0.001$ ). At inception, $54.2 \%$ of men and $63.2 \%$ of women had any service connection-i.e., service connection for disorders other than $\operatorname{PTSD}(p=0.01)$ and similar total disability ratings $(p=0.50)$. However, by study's end, more men than women had any service connection $(88.5 \%$ versus $83.5 \%, p=0.05)$, and men's mean total disability rating was substantially greater than women's $(77.1 \pm 26.2$ versus $66.8 \pm 30.7, p<0.001)$. History of military sexual assault had the largest effect modification on men's versus women's odds of PTSD service connection.

Conclusion: Even after 2011, cohort men were more likely than the women to reverse initially denied PTSD claims, and military sexual assault history accounted for much of this difference. Service connection for other disorders initially offset women's lower rate of PTSD service connection, but, ultimately, men's total disability ratings exceeded women's. Gender discrepancies in service connection should be monitored beyond the initial claims period.

Keywords: Posttraumatic stress disorder, Gender, Cohort studies, Veterans disability claims, Compensation

\section{*Correspondence: Maureen.Murdoch@va.gov}

${ }^{1}$ Section of General Internal Medicine, Minneapolis VA Health Care System, One Veterans Drive (111-0), Minneapolis, MN 55417, USA Full list of author information is available at the end of the article

\section{Background}

The Department of Veterans Affairs' (VA) Veterans Benefits Administration (VBA) directs the United States' third largest federal disability program, second only to the Social Security Disability Insurance and Supplemental 
Security Income programs. Veterans indemnified by VA for disorders incurred or aggravated by military service receive disability ratings ranging from $0 \%$ (non-disabled) to $100 \%$ (completely disabled). Higher ratings are associated with greater compensation and other benefits. Veterans may be indemnified ("service connected" in VA parlance) for multiple disorders, but their total disability rating can never exceed $100 \%$. The total disability rating is also called the "combined degree of service connection." Veterans denied service connection have multiple avenues to appeal their rulings. They may also open new claims for the same condition if they are able to provide new and material evidence.

Of the 4.4 million Veterans service-connected for military-related disorders in 2016, almost $20 \%$ were indemnified for posttraumatic stress disorder (PTSD) [1]. Compared to Veterans who apply for but do not receive PTSD service connection, successful claimants are more likely to engage with outpatient VA mental health services, to demonstrate clinically relevant improvements in PTSD symptoms 10 years later, and to have less poverty and homelessness [2-5]. PTSD service connection is especially important in reducing poverty for men who self-identify as disabled or as African American [6]. PTSD service connection therefore influences well-being across multiple domains, and it is critical that all Veterans eligible for these benefits receive them.

Historically, 71\% of women filing VA PTSD disability claims do so based on military sexual assault experiences, whereas more than $90 \%$ of men file PTSD disability claims based on combat exposure [7]. As a result, women are granted PTSD service connection less frequently than men are $[7,8]$ : it is simply easier to establish evidence of combat exposure than of military sexual assault $[9,10]$. Although VBA had developed strategies to counter this difficulty since the early 1990s [11], in 2011 they distributed further guidance and training to the field to "ensure consistency and fairness" in developing military sexual trauma claims [12, p. 3]. Specifically, when witnesses and police reports did not exist, claims processors were charged to look for alternative markers of sexual assault, such as sudden, proximate behavior changes (e.g., upticks in drinking, taking more sick leave), requests for job transfers, or requests for HIV or pregnancy testing, to name just a few. Aimed at initial claims, this development could also have encouraged more women with previously denied PTSD disability claims to file appeals and, once filed, to prevail.

Our first goal was to examine the impact of this 2011 initiative on previously denied claims by taking advantage of a long-standing, well-characterized cohort of men and women who applied for PTSD disability benefits between 1994 and 1998 [4, 7, 13]. As of 2007, 50\% of men in this cohort, compared to $42 \%$ of women, had successfully reversed their initial PTSD claims' denials [14]. Here, we re-visit the cohort to see if men and women's reversal rates would be more similar after 2011.

Our second goal was to see if service connection for other disorders might offset any persisting gender differences. In 2010, the VA's Office of the Inspector General [8], found that, at the time of initial claim, women were less likely than men to receive PTSD service connection but more likely to receive service connection for other mental disorders. They argued that this substitution prevented women from experiencing a net welfare loss. If men filing PTSD disability claims received $70 \%$ disability ratings for PTSD, for example, while women filing PTSD disability claims received $70 \%$ disability ratings for depression, then their base compensation packages would be the same. Such substitutions could explain why, 2 years after filing an initial PTSD disability claims, poverty rates were similar in women with and without PTSD service connection [6]. Because the present study focuses exclusively on Veterans with denied initial claims, we anticipated, based on the 2010 VA Inspector General report, that the women would be more likely than the men to be service connected for other disorders. For net parity, however, men and women's total disability rating would need to be similar.

Our third goal was to identify reasons for any persistent gender discrepancies. We have previously shown in this cohort that older age, white race, service during the Vietnam Conflict, married status, and having a VA chart diagnosis of PTSD were each associated with higher odds of obtaining initial PTSD service connection or with successfully reversing a denial pre-2011 [14-16]. It made sense that these effects would carry through after 2011. A history of combat exposure instead of military sexual assault also predicted lower odds of PTSD service connection upon initial claim [7] but was less influential on odds of successfully reversing a denied claim prior to 2011 [14]. In the present analysis, our goal was to determine whether trauma type affected claims decisions at all after the 2011 guidance.

\section{Methods}

\section{Study design}

The study is a post hoc, secondary analysis of an ambispective cohort (ambispective $=$ retrospective and prospective elements).

\section{Participants}

Between 1998 and 2000, we randomly selected 2700 men and 2700 women (total $N=5400$ ) from a population of 100,750 men and 3866 women who applied for Department of Veterans Affairs PTSD disability benefits 
between 1994 and 1998. The inception cohort are the 1654 men and 1683 women who responded to a mailed survey between 1998 and 2000. We assessed service connection outcomes for the cohort on Dec 31, 1999 (Time 1), April 30, 2007 (Time 2), and August 24, 2016 (Time 3). The present study is limited to the 253 men and 663 women cohort members whose original, Time 1, PTSD disability claims were denied and who were alive at Time 3. Women outnumber the men in the present study because they were substantially more likely to have their initial PTSD disability claims denied. The Minneapolis VA Health Care System's Human Studies Subcommittee reviewed and approved the study protocol.

\section{Outcomes}

The primary outcome was Veterans' PTSD service-connected status as of August 24, 2016 (Time 3). Secondary outcomes included Veterans' service-connected status for any disorder at all three time points, and their total disability rating (combined degree of service connection) at all 3 time points. Note that, for Veterans who reversed their PTSD claims' denials, the Time 2 and 3 total disability rating will include their service rating for PTSD as well as for other disorders.

\section{Main independent variable}

The independent variable of interest was gender, dichotomized as male or female. Gender was obtained at Time 1 from the Veterans Issues Tracking Adjudication Log.

\section{Potential confounders}

Confounders available for the entire study sample included: age, race, service era, combat and military sexual trauma exposures, married status at Time 1, and having at least one VA chart diagnosis of PTSD between 1994 and 2006.

\section{Data sources}

We used VA administrative databases to obtain Veterans' age, service era (categorized as during the Vietnam Conflict versus later), and service connection information. To determine if Veterans had been diagnosed with PTSD between 1994 and 2006, we used International Classification of Diseases, Ninth Revision, Clinical Modification (ICD-CM-9) codes housed in the VA National Patient Care Database. Veterans with any ICD-CM-9 code for PTSD between 1994 and 2006 were categorized as having a chart diagnosis of PTSD.

We used self-reported, single-item questions from the Time 1 survey to determine Veterans' married status and race. The Time 1 survey also assessed Veterans' combat exposure using a modified, 22-item version of the Combat Exposure Index [17] and military sexual assault history, using a modified, 4-item version of the "criminal sexual misconduct" subscale from the Sexual Harassment Inventory [18]. To be consistent with our prior analyses, combat and military sexual assault were dichotomized into "any" versus "none" variables.

\section{Analysis}

We used $x^{2}$ tests and ANOVA to compare unadjusted gender differences in the primary and secondary outcomes. To identify potential confounders, we first used $x^{2}$ tests and ANOVA to compare characteristics between those who were and were not service connected for PTSD at Time 3 and to compare men and women's characteristics. We then used sufficient summary analysis $[19,20]$ to assess the direct effect of gender on Veterans' odds of Time 3 PTSD service connection after controlling for identified confounders. To this end, we used sufficient summary score analysis both as subclassification on dimension-reducing, sufficient summary scores and as a covariance adjustment.

Sufficient summary scores are an extension of propensity analysis [21]. To develop dimension-reducing, sufficient summary scores, all predictors associated with Time 3 PTSD service connection in unadjusted analyses at $\mathrm{p} \leq 0.10$ were simultaneously submitted to multiple logistic regression within each gender (see Additional file 1: Tables S1 and S2). Age correlated 0.81 with service before or after the Vietnam Conflict; therefore, only service before or after the Vietnam Conflict was included in analyses. Correlations among the other predictors ranged from -0.35 to 0.24 . Variables associated with Time 3 PTSD service connection at $\mathrm{p} \leq 0.05$ in either gender were retained such that the final four predictors used to create sufficient summary scores and to assess confounding were: service during or after the Vietnam Conflict, chart diagnosis of PTSD, history of military sexual assault, and history of combat. Thus, each Veteran's summary score corresponded to his or her probability of Time 3 PTSD service connection, based on their unique combination of the 4 variables. For the subclassification analysis, we created 3 summary score strata instead of the usual 5 because of sparse data. The summary score strata ranged from low probability $(<0.38, n=347)$ of PTSD service connection to medium probability $(\geq 0.38$ and $\leq 0.55, n=341)$ to high probability $(>0.55, n=228)$.

We also examined the degree to which each of the four variables changed the unadjusted association between gender and Time 3 PTSD service connection. If the gender effect size changed $10 \%$ or more after adjustment, we considered that evidence of mediating confounding [22]. The change in effect size was calculated as the absolute difference between the unadjusted and adjusted association between gender and Time 3 PTSD service 
connection, divided by the unadjusted association and multiplied by $100 \%$. We also report the study's E-value [23] with $95 \%$ confidence intervals (CI). E-value measures how high an association between unmeasured mediating confounder(s), gender, and PTSD service connection would need to be to explain away any remaining associations between gender and Time 3 PTSD service connection after adjusting for the sufficient summary score. We used SPSS Version 19 for all analyses.

\section{Results}

\section{Sample descriptives}

Men's mean age when they originally filed their claims was $45.5( \pm 7.2)$ years, and women's, $37.2( \pm 8.5)$ years. By Time 3, men's mean age was $65.3( \pm 7.2)$ years and women's, $57.1( \pm 8.6)$ years $(p s<0.001)$. Table 1 shows the sample's categorical sociodemographic characteristics, stratified by those who did and did not become service connected for PTSD by Time 3 and stratified by gender. As seen from Table 1, relative to their counterparts, Veterans who became service connected for PTSD by Time 3 were more likely to have served during the Vietnam Conflict, to have a combat history, and to have a PTSD chart diagnosis. Many of these predictors, particularly service during Vietnam, combat exposure, and military sexual assault history, also differed by gender.

\section{Changes in PTSD service connection}

Figure 1 shows that PTSD service connection status was dynamic, with individual gains and losses over the study's course. Of the 127 men and 279 women who gained PTSD service connection at Time 2, women were twice

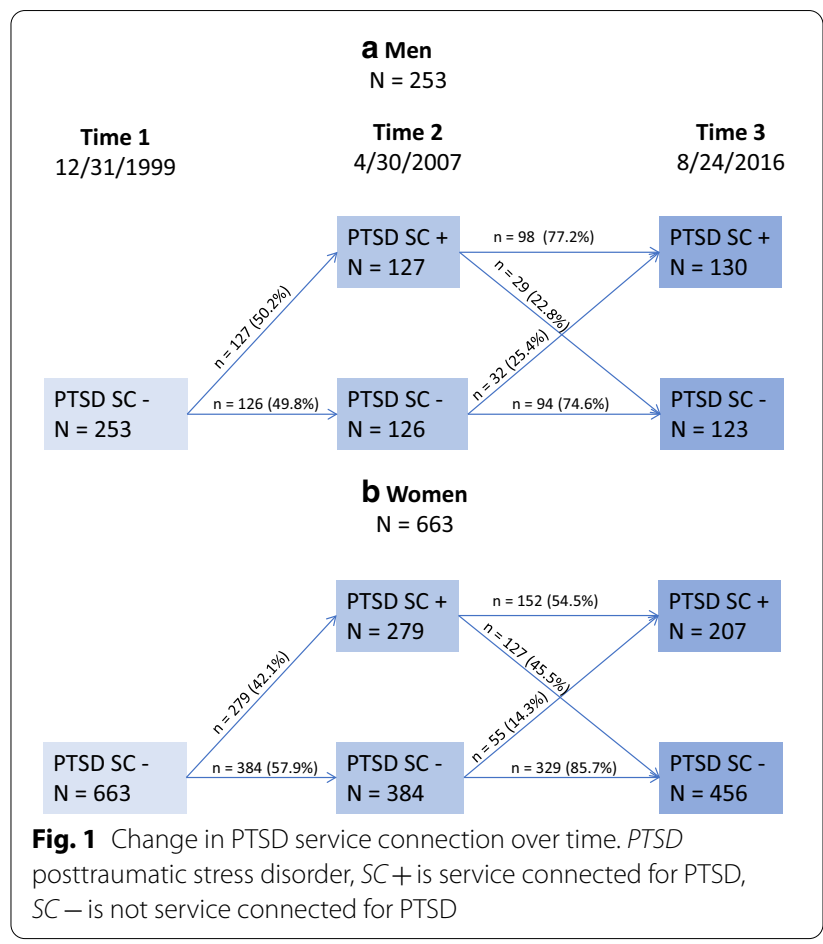

as likely as the men to have lost it again by Time 3 . The net gain in PTSD service connection by Time 3 was 130 (51.4\%) men and 207 (31.3\%) women.

\section{Other service connection outcomes}

Although women were less likely to be service connected for PTSD at any time point, Table 2 shows that, as expected, statistically significantly more women than

Table 1 Sociodemographic Characteristics of the Sample, Stratified by Time 3 PTSD Service Connection Status and Stratified by Sex

\begin{tabular}{|c|c|c|c|c|}
\hline \multirow[t]{3}{*}{ Characteristic } & \multicolumn{2}{|c|}{ Time 3 PTSD service connection status } & \multicolumn{2}{|l|}{ Sex } \\
\hline & $\begin{array}{l}S C- \\
N=579\end{array}$ & $\begin{array}{l}\mathrm{SC}+ \\
\mathrm{N}=337\end{array}$ & $\begin{array}{l}\text { Men } \\
N=253\end{array}$ & $\begin{array}{l}\text { Women } \\
N=663\end{array}$ \\
\hline & $n(\%)$ & $n(\%)$ & $n(\%)$ & $n(\%)$ \\
\hline \multicolumn{5}{|l|}{ Race/ethnicity } \\
\hline White & $371(64.1 \%)$ & $220(65.3 \%)^{* * *}$ & $164(64.8 \%)$ & $427(64.4 \%)^{* * *}$ \\
\hline Black or African American & $150(25.9 \%)$ & $87(25.8 \%)^{* * *}$ & $64(25.3 \%)$ & $173(26.1 \%)^{* * *}$ \\
\hline Hispanic & $31(5.4 \%)$ & $17(5.0 \%)^{* * *}$ & $16(6.3 \%)$ & $320(4.8 \%)^{* * *}$ \\
\hline Other & $46(7.9 \%)$ & $31(9.2 \%)^{* * *}$ & 19) $0(7.5 \%$ & $580(8.7 \%)^{* * *}$ \\
\hline Served during Vietnam Conflict & $199(34.4 \%)$ & $167(49.6 \%)^{* * *}$ & $207(81.8 \%)$ & $159(24.0 \%)^{* * *}$ \\
\hline Married at Time 1 & $230(60.3 \%)$ & $124(36.8 \%)^{* * *}$ & $122(48.2 \%)$ & $232(35.0 \%)^{* * *}$ \\
\hline History of combat exposure & $220(38.0 \%)$ & $184(54.6 \%)^{* * *}$ & $220(87.0 \%)$ & $184(27.8 \%)^{* * *}$ \\
\hline History of military sexual assault & $273(47.2 \%)$ & $173(51.3 \%)^{* * *}$ & $16(6.3 \%)$ & $430(64.9 \%)^{* * *}$ \\
\hline Any PTSD diagnosis, 1994-2006 & $328(56.6 \%)$ & $301(89.3 \%)^{* * *}$ & $180(71.1 \%)$ & $449(67.7 \%)^{* * *}$ \\
\hline
\end{tabular}

PTSD posttraumatic stress disorder, $S C$ - not service connected, $S C+$ is service connected

${ }^{*} p<0.05 ;{ }^{* *} p<0.01 ;{ }^{* * *} p<0.001$ 
Table 2 Service connection outcomes over time

\begin{tabular}{|c|c|c|c|}
\hline Service connection outcomes & $\begin{array}{l}\text { Men } \\
\mathrm{N}=253 \\
n(\%)\end{array}$ & $\begin{array}{l}\text { Women } \\
\mathrm{N}=663 \\
n(\%)\end{array}$ & $\mathrm{p}$ value \\
\hline \multicolumn{4}{|l|}{ Service connected for any disorder } \\
\hline At Time $1^{\text {a }}$ & $137(54.2)$ & $419(63.2)$ & 0.01 \\
\hline At Time 2 & $201(79.4)$ & $506(76.3)$ & 0.05 \\
\hline \multirow[t]{2}{*}{ At Time 3} & $224(88.5)$ & $553(83.5)$ & 0.05 \\
\hline & Mean (SD) & Mean (SD) & \\
\hline \multicolumn{4}{|c|}{$\begin{array}{l}\text { Total disability ratings (combined degree of service } \\
\text { connection) }\end{array}$} \\
\hline At Time 1 & $25.4(27.4)$ & $27.0(23.3)$ & 0.50 \\
\hline At Time 2 & $65.3(28.4)$ & $57.8(28.9)$ & 0.001 \\
\hline At Time 3 & $77.1(26.2)$ & $66.8(30.7)$ & $<0.001$ \\
\hline
\end{tabular}

a No one in the sample was service connected for posttraumatic stress disorder at Time 1

b Among those with any service connection for any disorder

men were service connected for disorders other than PTSD at Time 1; their mean total disability rating (combined degree of service connection) was about the same as men's. Over time, however, men's net total disability rating increased at a higher rate than did the women's and was substantially higher than the women's by Time 3 . Additional file 1: Figure S1 shows that, for both men and women, total disability ratings skewed rightward with time. However, a greater proportion of men than women had total disability ratings of $100 \%$ by Time 3 .

\section{Sufficient summary analysis and confounding}

Overall, men's mean sufficient summary score, which corresponds to their mean probability of Time 3 PTSD service connection, was $0.45 \pm 0.19$, compared to women's mean sufficient summary score of $0.34 \pm 0.18(p<0.001)$. Stratifying by sufficient summary class improved balance in observed variables between those who were and were not service connected for PTSD at Time 3 (Additional file 1: Table S3), but imbalances in the highest stratum remained. The association, $\beta$, between gender and Time 3 PTSD service connection was 0.46 , with mean weighted variance $=0.04 ; z=2.42, p=0.02$. This analysis therefore suggested that men had statistically significantly higher odds of Time 3 PTSD service connection than did women after controlling for available confounders.

Table 3 shows the modifying effect of each potential confounder on gender's association with Time 3 PTSD service connection. The final row shows results of covariance adjustment on the sufficient summary score, which indicated that men had 1.52 higher odds of gaining PTSD service connection at Time 3 than did women after controlling for all available confounders. Only chart diagnosis of PTSD failed to meet criterion for confounding. History of military sexual assault had the largest impact on the odds ratio between male gender and PTSD service connection. When military sexual assault was included in the model, the odds of men

Table 3 Sex's association with time 3 PTSD service connection after controlling for other potential confounders

\begin{tabular}{|c|c|c|c|c|c|c|c|c|}
\hline \multirow[t]{2}{*}{ Controlling for: } & \multicolumn{7}{|c|}{ Association between gender and PTSD service connection } & \multirow{2}{*}{$\begin{array}{l}\text { Size of effect } \\
\text { modification } \\
(\%)\end{array}$} \\
\hline & $\beta$ & SE & Wald $x^{2}$ & df & p value & OR & $95 \% \mathrm{Cl}$ & \\
\hline Nothing (unadjusted) & 0.845 & 0.15 & 31.26 & 1 & $<0.001$ & 2.33 & $1.73,3.13$ & - \\
\hline Service during Vietnam & 0.672 & 0.18 & 14.32 & 1 & $<0.001$ & 1.96 & $1.38,2.77$ & 15.9 \\
\hline PTSD chart diagnosis & 0.907 & 0.16 & 30.81 & 1 & $<0.001$ & 2.48 & $1.80,3.41$ & 6.4 \\
\hline Military sexual assault history & 1.420 & 0.20 & 51.97 & 1 & $<0.001$ & 4.14 & $2.81,6.09$ & 77.7 \\
\hline Combat history & 0.630 & 0.18 & 12.55 & 1 & $<0.001$ & 1.88 & $1.33,2.66$ & 19.3 \\
\hline Sufficient summary score ${ }^{a}$ & 0.420 & 0.17 & 6.284 & 1 & 0.01 & 1.52 & $1.10,2.11$ & 34.8 \\
\hline
\end{tabular}

PTSD posttraumatic stress disorder, SE standard error, OR odds ratio; OR $>1$ indicates men have greater odds of having PTSD service connection at Time 3 than women. $\mathrm{Cl}$ confidence intervals

- Not applicable

a Sufficient summary score simultaneously adjusts for service during Vietnam, PTSD chart diagnosis, military sexual assault history, and combat history 
being service connected for PTSD compared to women increased from an unadjusted odds ratio of 2.33 to an adjusted odds ratio of 4.14 (77.7\% effect modification). Adjusting for all the predictors simultaneously using the sufficient summary score resulted in an overall, $34.8 \%$ effect modification on the association between gender and PTSD service connection. E-value for the association between gender and Time 3 PTSD service connection was 1.77 (95\% CI 1.28).

\section{Discussion}

Although substantial proportions of men and women in this cohort ultimately became service connected for PTSD after 2011, the men were significantly more likely to do so than women. Consistent with the VA's Office of the Inspector General's [8] 2010 report, men and women had the same net, total disability rating at Time 1 . From Time 2 forward, however, men's net total disability ratings persistently exceeded women's. Therefore, service ratings for other disorders did not offset women's lower, long-term odds of PTSD service connection.

In the present study, three predictors-service during Vietnam, history of military sexual assault, and history of combat-were unevenly distributed by gender and explained some, but not all, of the gender difference in Time 3 PTSD service connection. Chart diagnosis of PTSD independently predicted Time 3 PTSD service connection but was evenly distributed by gender. History of military sexual assault had the largest confounding effect on the association between gender and Time 3 PTSD service connection, followed by combat exposure. This is perhaps unsurprising, because, by law, Veterans' selfreport is enough to establish credible evidence of combat exposure if it is "consistent with the circumstances, conditions, or hardships of [their] service" [9], but self-report is not enough to establish credible evidence of military sexual assault [10]. As women are more likely than men to file military sexual assault claims, much of the gender discrepancy in initial claims' approvals has been attributed to this disparate burden of proof [8]. Despite VBA's attempt to reduce the challenges associated with military sexual assault claims, our data indicates that gender discrepancies carried into the appeals process, even after 2011. More recently, the Office of Inspector General [12] identified processing errors in almost half the military sexual trauma claims denied in fiscal year 2017. Whether these errors might have applied to even earlier yearsthus contributing to our observed gender differences, is uncertain. We must also acknowledge that, had the VBA not implemented stronger processes for military sexual assault claims, the gender differences seen here may have been even greater.

\section{Strengths and limitations}

To our knowledge, this is the longest-running study of PTSD service connection outcomes available. Our reliance on administrative and inception survey data to define confounders was a strength in that we had no missingness in those variables. Each candidate confounder had varied by gender in previous work and was either known or hypothesized to be associated with PTSD service connection. Nonetheless, it seems likely that we had an insufficient set of confounders to fully explain observed gender differences in Time 3 PTSD service connection. One might easily imagine some set of unmeasured variables associated with both gender and Time 3 PTSD service connection at an odds ratio of 1.77 . In an earlier analysis, milder PTSD symptoms and better net functioning partially explained why women were less likely than the men to have Time 2 PTSD service connection [14]. We did not have access to similar variables for the entire cohort at Time 3. Thus, the observed, persistent gender difference in service connection outcomes at Time 3 could be at least partially attributable to gender differences in clinical recovery.

In one regional cohort comprised of $99 \%$ men, $83 \%$ of Veterans denied service connection for PTSD said they planned to appeal [2]. However, we do not know if these Veterans' intentions generalize nationally or to women or if Veterans followed through with their stated intentions to appeal. Relative to men, women may be less likely to file claims' appeals or to access skilled advocates during the appeals process. If so, these could be potential intervention points for narrowing the gender gap we observed here. Furthermore, to our knowledge, VBA did not widely advertise their 2011 process changes. Women with claims denied prior to 2011 may not have known about the changes and thus may not have filed subsequent appeals. This study did not have access to Veterans' claims appeals data. Since appeals play a causal role in reversing denied disability claims, future studies should specifically test for gender differences in appeal rates and outcomes.

We created this cohort based on the calendar years in which Veterans initially applied for PTSD service connection. The sample is representative of claimants from those years, but cohort men and women nonetheless differed substantially on many characteristics, complicating direct comparisons. Despite a reasonably large sample, sufficient summary analysis could not overcome problems with sparse data in our highest stratum of probability for PTSD service connection. Selecting men and women from the same service era might improve their comparability and reduce sparse data problems in future research. The present cohort excludes post-9/11 Veterans: findings may not apply to them. 


\section{Policy implications}

Women are now the fastest growing demographic of US Veterans and account for almost $15 \%$ of active duty troops [24]. When the affected population is large, as in this case, even small disparities may carry large impacts. We have shown that, even after 17 years, the appeals or reapplication process does not reduce initial gender differences in PTSD service connection. However, women Veterans with previously denied claims may not have been made aware of the 2011 changes in VBA's procedures. For these reasons, attention to claims outcomes should not be limited to just initial claims. While service connection for other disorders may have offset gender differences in PTSD service connection at first, men's combined degree of service connection eventually exceeded women's. Because PTSD service connection is associated with several important outcomes, including treatment engagement and symptom reduction $[2-5,25]$, we must ensure that observed gender differences reflect appropriate sources of variation. Besides service during Vietnam, military sexual assault history, and combat exposure, there are probably multiple other variables that differ by gender and influence long-term PTSD service connection. Identifying and addressing them would ensure equity, transparency, and confidence in the VA's indemnity program.

\section{Conclusions}

Planned, prospective investigations are needed to understand how Veterans' service-connected status changes over time-for PTSD and for other disorders-and how they differ by gender. These studies should include indepth assessments of Veterans' clinical characteristics, such as disease severity; process variables, such as how initial claims, re-evaluations and appeals are handled; and associated outcomes, such as homelessness and work, role, and social functioning.

\section{Supplementary Information}

The online version contains supplementary material available at https://doi. org/10.1186/s12905-021-01214-7.

Additional file 1: Table S1. Characteristics associated with time 3 PTSD service connection within each sex. Table S2. Predictors of Time 3 PTSD service connection for men and for women. Results of multiple logistic regression. Table S3. Predictors of Time 3 PTSD Service connection after stratifying by sufficient summary class. Figure $\mathbf{S} 1$. Change in the distribution of total disability ratings by time, stratified by sex.

\section{Abbreviations}

ANOVA: Analysis of variance; Cl: Confidence intervals; ICD-9-CM: International Classification of Diseases, Clinical Modification, 9th revision; PTSD: Posttraumatic stress disorder; SC + : Is service connected for PTSD; SC - : Is not service connected for PTSD; VA: Department of Veterans Affairs; VBA: Veterans Benefits Administration.

\section{Acknowledgements}

Not applicable.

\section{Authors' contributions}

MM obtained funding; designed the study; oversaw data collection, analysis, and interpretation; and drafted the manuscript. SN contributed to data analysis. MRS, NAS, SMKF, and SN contributed to data interpretation and manuscript revisions. All authors read and approved the final manuscript.

\section{Funding}

The Center for Care Delivery Outcomes Research is a VA Health Services Research and Development (HSR\&D) Service Center of Innovation (Center Grant \#HFP 98-001). This work was supported by the VA HSR\&D Service (Grant Numbers IIR-09-359, CIN-13-406). The funder had no role in data analysis, manuscript preparation, or decision to publish.

\section{Availability of data and materials}

The data that support the findings of this study are available from the corresponding author (MM) upon reasonable request and with local Minneapolis VA Health Care System IRB permission.

\section{Ethics approval and consent to participate}

The Minneapolis VA Health Care System's Internal Review Board (IRB) for Human Studies reviewed the study protocol (\#3337-A). The IRB granted this study a HIPAA waiver for written documentation of informed consent because it was considered a minimal risk study. Potential participants were mailed an IRB-approved cover letter with each survey that discussed the risks and benefits of taking part in the study and emphasized the voluntary nature of completing the survey. Participants'signified their consent to participate in the research by returning a completed survey. Their returned, completed survey was considered documentation of their consent to participate.

\section{Consent for publication}

Not applicable.

\section{Competing interests}

The authors declare they have no competing interests.

\section{Author details}

1 Section of General Internal Medicine, Minneapolis VA Health Care System, One Veterans Drive (111-0), Minneapolis, MN 55417, USA. ${ }^{2}$ Center for Care Delivery and Outcomes Research, Minneapolis VA Health Care System, One Veterans Drive (152), Minneapolis, MN 55417, USA. ${ }^{3}$ Department of Internal Medicine, University of Minnesota Medical School, 420 Delaware St SE, Minneapolis, MN 55455, USA. ${ }^{4}$ National Centers for PTSD, Pacific Islands Division, Department of Veterans Affairs, 3375 Koapaka Street, Suite I-560, Honolulu, HI 96819, USA. ${ }^{5}$ Department of Psychiatry, University of Minnesota Medical School, F282/2A West Building, 2450 Riverside Avenue S, Minneapolis, MN 55454, USA. ${ }^{6}$ National Center for PTSD Women's Health Sciences Division at VA Boston Healthcare System, 150 S Huntington Ave, Boston, MA 02130, USA.

Received: 4 June 2020 Accepted: 8 February 2021

Published online: 16 February 2021

\section{References}

1. Veterans Benefits Administration. Annual benefits report: fiscal year 2016: compensation. Washington DC: US Department of Veterans Affairs; 2016. p. 52.

2. Sayer N, Spoont M, Nelson D, Clothier B, Murdoch M. Changes in psychiatric status and service use associated with continued compensationseeking after claim determinations for posttraumatic stress disorder. J Trauma Stress. 2008;21(1):40-8.

3. Spoont M, Sayer N, Nelson D, Nugent S. Does filing a PTSD disability claim promote mental health care participation among veterans? Milit Med. 2007;172:572-5. 
4. Murdoch M, Sayer N, Spoont M, Rosenheck R, Noorbaloochi S, Griffin J, et al. Long-term outcomes of disability benefits in US Veterans with posttraumatic stress disorder. Arch Gen Psychiatry. 2011;68(10):1072-80.

5. Murdoch $M$, Jonk Y. Veterans' Health care utilization in Department of Veterans Affairs facilities two to twelve years after applying for PTSD service connection: findings from a nationally representative cohort. PsyArXiv. 2019. https://doi.org/10.31234/osf.io/haqbc.

6. Murdoch M, vanRyn M, Hodges J, Cowper D. Mitigating effect of Department of Veterans Affairs (VA) disability benefits for PTSD on low income. Milit Med. 2005;170(2):137-40.

7. Murdoch M, Hodges J, Hunt C, Cowper D, Kressin N, O'Brien N. Gender differences in service connection for PTSD. Med Care. 2003;41(8):950-61.

8. Department of Veterans Affairs, Office of Inspector General. Review of combat stress in women veterans receiving VA Health Care and disability benefits. Washington, DC: Dept. Veterans Affairs Office of Inspector General; 2010 Dec 16. Report No.: 10-01640-45.

9. Veterans Benefits, 38 CFR $\$ 3.304(f, 2), 2000 a$.

10. Veterans Benefits, 38 CFR $\$ 3.304(f, 5), 2000 b$.

11. Hunt C. Women veterans issues, part 1: developing PTSD sexual assault claims in: C\&P training operations teleconference. VBA Satellite Training Tele-conference. Washington, DC. 1996.

12. Department of Veterans, Affairs Office of Inspector General. Veterans Benefits Administration: denied posttraumatic stress disorder claims related to military sexual trauma. Washington, DC: Dept. Veterans Affairs Office of Inspector General, Office of Audits and Evaluations; 2018 Aug 21. Report No.: 17-05248-241.

13. Murdoch M, Spoont M, Kehle-Forbes S, Harwood E, Sayer N, Clothier B, et al. Persistent serious mental illness among former applicants for VA PTSD disability benefits and long-term outcomes: symptoms, functioning, and employment. J Trauma Stress. 2017;30(1):36-44.

14. Sayer N, Hagel E, Noorbaloochi S, Spoont M, Rosenheck R, Griffin J, et al. Gender differences in VA disability status for PTSD over time. Psychiatr Serv. 2014;65(5):663-9.

15. Murdoch $M$, Hodges J, Cowper D, Fortier L, van Ryn M. Racial disparities in VA service connection for posttraumatic stress disorder disability. Med Care. 2003:41(4):536-49.
16. Murdoch M, Hodges J, Cowper D, Sayer N. Regional variation and other correlates of Department of Veterans Affairs (VA) disability awards for posttraumatic stress disorder. Med Care. 2005;43(2):112-21.

17. Janes G, Goldberg J, Eisen S, True W. Reliability and validity of a combat exposure index for Vietnam Veterans. J Clin Psychol. 1991;47(1):80-6.

18. Murdoch M, McGovern P. Development and validation of the Sexual Harassment Inventory. Violence Vict. 1998;13(3):203-16.

19. Noorbaloochi S, Nelson D, Asgharian M. Balancing and elimination of nuisance variables. Int J Biostat. 2010. https://doi. org/10.2202/1557-4679.1209.

20. Nelson D, Noorbaloochi S. Information-preserving sufficient summaries for dimension reduction. J Multivar Anal. 2013;115(March):347-58.

21. Rosenbaum P, Rubin D. The central role of the propensity score in observational studies for causal effects. Biometrika. 1983;70(1):41-55.

22. Bliss R, Weinberg J, Webster T, Vieira V. Determining the probability distribution and evaluating sensitivity and false positive rate of a confounder detection method applied to logistic regression. J Biom Biostat. 2012;3(4):142.

23. VanderWeele TJ, Ding P. Sensitivity analysis in observational research: introducing the E-value. Ann Intern Med. 2017;167(4):268-74.

24. National Center for Veterans Analysis and Statistics, Office of Policy and Planning. The past, present and future of women Department of Veterans Affairs; 2017 February. https://www.va.gov/womenvet/docs/women vet_history.pdf. Accessed 4 June 42020.

25. Sripada R, Hannemann C, Schnurr P, Marx B, Pollack S, McCarthy J. Mental health service utilization before and after receipt of a service-connected disability award for PTSD: findings from a national sample. Health Serv Res. 2018;53(8):4565-83.

\section{Publisher's Note}

Springer Nature remains neutral with regard to jurisdictional claims in published maps and institutional affiliations.
Ready to submit your research? Choose BMC and benefit from:

- fast, convenient online submission

- thorough peer review by experienced researchers in your field

- rapid publication on acceptance

- support for research data, including large and complex data types

- gold Open Access which fosters wider collaboration and increased citations

- maximum visibility for your research: over $100 \mathrm{M}$ website views per year

At BMC, research is always in progress.

Learn more biomedcentral.com/submissions 